\begin{tabular}{|c|c|c|}
\hline Fallupr $\mathrm{Dh}$ & Cell Physiol Biochem 2012;30:477-488 & \\
\hline in & DOI: $10.1159 / 000339029$ & $\begin{array}{l}\text { (c) } 2012 \text { S. Karger AG, Basel } \\
\text { www.karger.com/cpb }\end{array}$ \\
\hline & Accepted: May 14, 2012 & $1015-8987 / 12 / 0302-0477 \$ 38.00 / 0$ \\
\hline
\end{tabular}

\title{
Electrophysiological Effects of Lysophosphatidylcholine on HL- 1 Cardiomyocytes Assessed with a Microelectrode Array System
}

\author{
Sigfus Gizurarson* Yangzhen Shao* Azra Miljanovic Truls Råmunddal Jan Borén \\ Lennart Bergfeldt Elmir Omerovic
}

Department of Molecular and Clinical Medicine, Sahlgrenska Academy, University of Gothenburg, Gothenburg, Sweden, * Sigfus Gizurarson and Yangzhen Shao have contributed equally

\section{Key Words}

HL-1 cardiomyocytes - Lysophosphatidylcholine - Microelectrode array system • Electrophysiology • Field potential

\begin{abstract}
Background: Sudden death due to malignant ventricular arrhythmias is the most important cause of death in acute myocardial infarction. Improved knowledge about the pathophysiology underlying these arrhythmias is essential in the search for new anti-arrhythmic strategies. Lysophosphatidylcholine (LPC), a hydrolysis product of (membrane) phospholipid degradation, is one of the most potent pro-arrhythmic substances that accumulate in the human heart during myocardial ischemia. The aim of this study was to set up and validate an in vitro experimental system for studies on the effects of LPC on electrophysiological parameters in beating cardiomyocytes. Methods and Results: Spontaneously beating HL-1 cardiomyocytes were cultured on multielectrode array microchips for three days for the recording of electrical activities in the form of field potentials (FP). FPs were recorded at baseline and after addition of $2,4,8,12,16,20$, and $24 \mu \mathrm{M}$ of LPC to the cell medium $(n=9)$. We found that LPC could induce rapid effects on electrical parameters in the HL-1 cells. The overall half-maximal effective concentration $\left(\mathrm{EC}_{50}\right)$ of $\mathrm{LPC}$ was around $12 \mu \mathrm{M}$. The beating rate and peak-peak amplitude of FP thus decreased at concentrations $\geq 12 \mu \mathrm{M}$ and were inversely proportional to increased LPC concentration. The duration of FP was significantly prolonged with LPC above $12 \mu \mathrm{M}$ and was concentration-dependent. LPC delayed signal propagation, an effect which was mimicked by blocking gap junctions with heptanol and attenuated by pre-treatment with isoprenaline and atropine. Finally, asynchronous activity was induced by LPC at $>12 \mu \mathrm{M}$. Conclusions: LPC induced prompt and pronounced electrophysiological alterations that may underlie its observed pro-arrhythmic properties. Our in vitro model with HL-1 cells and microelectrode array system may be a useful tool for preclinical studies of electrophysiological effects of various pathophysiological concepts.
\end{abstract}




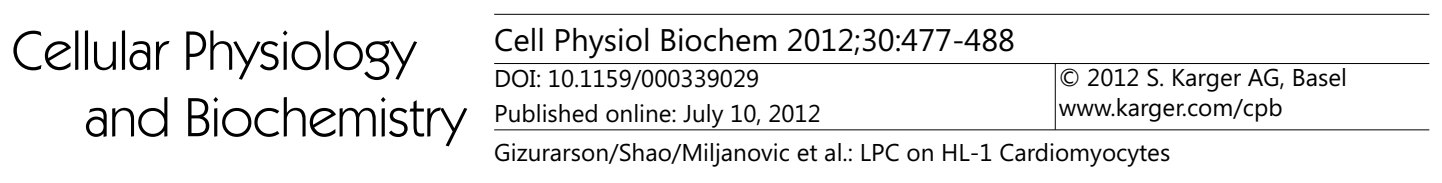

\section{Introduction}

Malignant ventricular arrhythmias are the major cause of sudden death in acute coronary syndromes and heart failure [1]. In ischemia, these arrhythmias occur early after the onset of myocardial ischemia and are therefore difficult to treat timely [2]. Understanding and prevention of lethal arrhythmias is an important research and clinical objective. In order to achieve this goal we need relevant experimental models.

Prior studies suggest that early-phase arrhythmic events are caused by accumulating metabolites in the ischemic myocardium [3]. Lysophosphatidylcholine (LPC) is an endogenous amphiphilic product of membrane degradation produced through the action of phosphalipase- $\mathrm{A}_{2}\left(\mathrm{PLA}_{2}\right)$. Under normal physiological conditions, accumulation of LPC is precluded by reacylation and hydrolysis [4]. In the setting of myocardial ischemia, activity of $\mathrm{PLA}_{2}$ increases while reacylation and washout of LPC decreases. Within the first few minutes after the onset of ischemia, LPC increases by $50-60 \%$ with a protracted normalization [5, 6]. LPC exerts various pro-arrhythmic effects. It inhibits fast $\mathrm{Na}^{+}$and inwardly rectifying $\mathrm{K}^{+}$ currents $[7,8]$. LPC causes intracellular $\mathrm{Ca}^{2+}$ accumulation and decreases cell-to-cell coupling [9-12]. The consequences of these alterations are slowed conduction and abnormal rhythmic activity (i.e. triggered activity and delayed after-depolarization, facilitating intramyocardial re-entry.

There are several in vitro and in vivo experimental models for studies of electrophysiological mechanisms. Patch-clamp techniques are suitable to study specific ion channels and the technique can be applied to whole cells. A significant limitation is the invasiveness of the method on the cellular level and the fact that it is limited to a single cell or a membrane patch. Optical mapping methods are less invasive and can be performed in living cellular syncytia including Langendorf preparations, but involve fluorescent bleaching and are sensitive to methodological artefacts. Microelectrode array recording (MEA) is an in vitro system for extra-cellular measurements of currents in the form of field potentials (FP) [13]. FP have been extensively studied and it has been shown that the information gained from analysis of FP closely correlates to the information gained by more invasive methodology i.e. intracellular recordings [14]. Recent technological developments in the field of microelectronic fabrication and amplifier design have improved the signal to noise ratio and the quality of recordings by MEA are now comparable to patch-clamp recordings. Furthermore, MEA technology offers the possibility to analyze impulse-generation, impulsepropagation, wave front velocity, and arrhythmic activity simultaneously [15].

The aim of this study was to set up and validate an experimental in vitro model for studies of electrophysiological alterations during LPC challenge of cardiomyocytes (HL-1 cells) using MEA technology.

\section{Materials and Methods}

\section{HL-1 cell culture}

HL-1 cell lines, which are derived from immortalized murine atrial cells, were a gift from Dr. William Claycomb (Louisiana State University Medical Center, New Orleans, LA). They express various ion channels, including $\mathrm{Na}^{+}, \mathrm{K}^{+}$and $\mathrm{Ca}^{2+}$ channels and have a phenotype similar to adult atrial cardiomyocytes [16]. The cells were grown in Claycomb medium (JRH Biosciences, KS) supplemented with $10 \%$ fetal bovine serum (JRH Biosciences, KS), $2 \mathrm{mM}$ L-glutamine, $100 \mu \mathrm{M}$ norepinephrine, $100 \mathrm{U} / \mathrm{ml}$ penicillin and $100 \mu \mathrm{g} / \mathrm{ml}$ streptomycin on flasks pre-coated with gelatin-fibronectin (BD Biosciences, PA). The medium was changed every $24 \mathrm{~h}$. In the experiments the cells were kept at $37^{\circ} \mathrm{C}$ in room air. Under these circumstances the cells are stable for long periods of time, far exceeding the time frame of the pharmacological challenge.

Solution preparations for LPC experiment

1-Palmitoyl-sn-glycero-3-phosphocholine, i.e. LPC-16 (in this article referred to as LPC), was purchased as powder ( $>99 \%$ purity) (Sigma-Aldrich, St. Louis, MO, USA). In order to solubilize LPC in phosphate- 


\section{Cellular Physiology and Biochemistry

\begin{tabular}{l|l}
\hline Cell Physiol Biochem 2012;30:477-488 \\
\hline \begin{tabular}{l|l}
\hline DOI: $10.1159 / 000339029$ & $\begin{array}{l}\text { @ 2012 S. Karger AG, Basel } \\
\text { www.karger.com/cpb }\end{array}$ \\
\hline Published online: July 10, 2012 & Gizurarson/Shao/Miljanovic et al. LPC on HL-1 Cardiomyocytes
\end{tabular}
\end{tabular} \\ Gizurarson/Shao/Miljanovic et al.: LPC on HL-1 Cardiomyocytes}

buffered saline (PBS) as micelles, it was first dissolved in chloroform/methanol and then dried under a stream of nitrogen, re-suspended in PBS, and sonificated [17]. LPC solutions were prepared in different concentrations by diluting the LPC solution in cell culture medium. LPC was added to the cell medium and stirred gently with a pipette before recording.

Atropine and isoprenaline (ISO) were obtained in clinically available ampules. Heptonal was purchased from Sigma-Aldrich (H3003, Sweden). These agents were added directly into cell culture medium at each desired testing concentration.

\section{Protocol of pharmacological treatment in LPC experiment}

HL- 1 cells were exposed to LPC at $2 \mu \mathrm{M}, 4 \mu \mathrm{M}, 8 \mu \mathrm{M}, 12 \mu \mathrm{M}, 16 \mu \mathrm{M}, 20 \mu \mathrm{M}$ and $24 \mu \mathrm{M}$, respectively. All concentrations were tested in one MEA plate and washout was performed 3 times with cell media between each two neighbouring concentrations. Electrical signals were recorded before and $3 \mathrm{~min}$ after LPC additions of each concentration (Fig. 1A).

In subsequent experiments, HL-1 cardiomyocytes were pre-treated with muscarinic receptor antagonist (Atropine, $50 \mu \mathrm{M}$ ) or $\beta$-adrenoceptor agonist (isoprenaline, ISO, $10 \mu \mathrm{M}$ ) 3 min before LPC challenge. The atropine/isoprenaline cell medium was removed before adding LPC. Finally, we tested heptanol (a selective gap-junction blocker) at 200, 250, 500, 600 and $700 \mu \mathrm{M}$ in the same manner as LPC. Heptanol at $800 \mu \mathrm{M}$, put out signals completely and no analysis at this dose was possible.

\section{MEA recordings}

HL-1 cardiomyocytes (100 000-250 000) were seeded on sterile gelatine-coated MEA plates. This coating was chosen because it was superior both to no coating and to gelatine/fibronectin coating as judged by better cell adherence and better signal quality in the MEA recordings. The cells were allowed to grow for three days in culture until homogenous growth and synchronous beating was observed in light microscopy. Cell cultures not showing this pattern, i.e. those showing insufficient growth, overgrowth, or no beating, were discarded. After the attachment and confluence of beating HL-1 cardiomyocytes, extracellular recordings were performed using a MEA data acquisition system (Multi Channel Systems, Reutlingen, Germany). The standard substrate-integrated MEA culture dish contains 60 Titanium Nitride coated gold electrodes $(30 \mu \mathrm{m}$ diameter) arranged in an 8x8 electrode grid with an inter-electrode distance of $200 \mu \mathrm{m}$. The system allows simultaneous recording of extracellular potentials from all electrodes at a sampling rate of $10 \mathrm{kHz}$. The integral heating device maintains the temperature stable at $37^{\circ} \mathrm{C}$.

\section{Analysis of MEA recordings}

All data were analyzed off-line using dedicated software MC_Rack version 3.9 (Multi Channel Systems, Reutlingen, Germany) or a customized toolbox programmed with MATLAB (The Mathworks, Natick, MA, USA). The following parameters were analyzed as previously described [18]: beating rate (BR), FP duration $\left(\mathrm{FP}_{\text {dur }}\right)$, rise time of $\mathrm{FP}$ upstroke $\left(\mathrm{FP}_{\text {rise }}\right)$ and peak-peak $\mathrm{FP}$ amplitude $\left(\mathrm{FP}_{\mathrm{AMP}}\right)$. The nomenclature is demonstrated in Fig. 1B. $\mathrm{FP}_{\text {rise }}$ is the time span required for the decline of the voltage from baseline to $\mathrm{FP}_{\mathrm{Min}}$ (Fig 1B). It has been demonstrated that $\mathrm{FP}_{\text {rise }}$ correlates well with the upstroke of the action potential [19].

Within a single MEA chip, FP morphologies varied between electrodes and $\mathrm{FP}_{\mathrm{Max}}$ (the last positive peak in FP) was not always easily detected in the offline analysis. One specific electrode with a clearly detectable $\mathrm{FP}_{\text {Min }}$ and $\mathrm{FP}_{\text {Max }}$ was chosen for analysis; 20 successive FPs from this electrode were averaged to derive mean values for the predefined parameters. The pharmacological effects of tested compounds on electrophysiological properties of HL-1 cells can be revealed by the repeated, comparative analysis of these electrical parameters on the same electrode before and after the compound addition within the same preparation. In addition, a concentration-effect curve for each parameter was developed after normalization for the parameters at baseline. The half maximum effect concentration $\left(\mathrm{EC}_{50}\right)$ was then derived by fitting the concentration-effect curve with Boltzmann function.

Propagation velocity was evaluated as previously described [20]. We included the MEA plates that had initial signals (pacemakers) lying at one of the four edges of the 8x8 electrode matrix. The total propagation distance was a constant of around $1400 \mu \mathrm{m}$. Propagation velocity was then evaluated in the form of propagation time, i.e. the time required for signals propagating from the "pacemaker" site to the other edge of the electrode matrix (Fig. 6D).

\section{Statistical analysis}

Data are presented as the mean \pm S.E.M. Repeated measures ANOVA was used for the analysis of FP parameters after the exposure to the different LPC and heptanol concentrations. Concentration-effect was 


\section{Cellular Physiology \\ Cell Physiol Biochem 2012;30:477-488 \\ and Biochemistry \\ DOI: 10.1159/000339029 \\ Published online: July 10, 2012 \\ (c) 2012 S. Karger AG, Basel \\ www.karger.com/cpb}

A

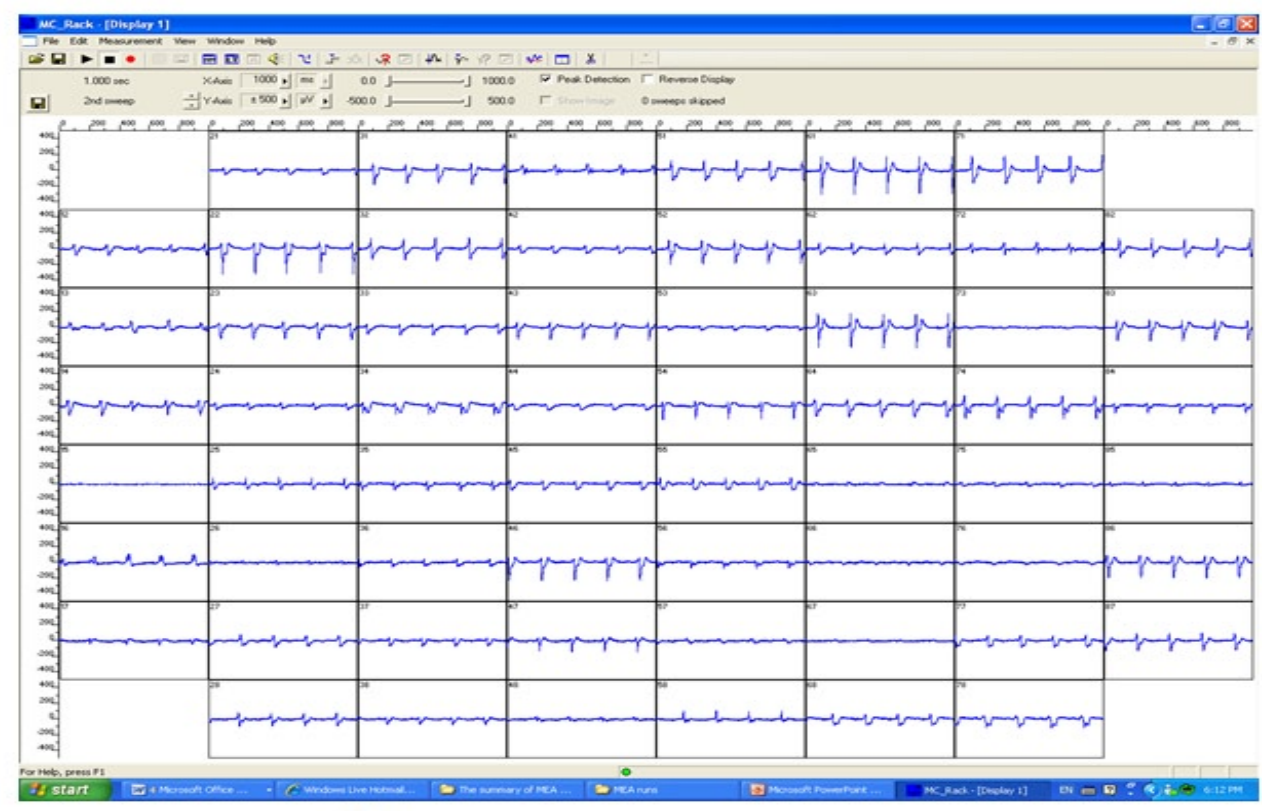

B

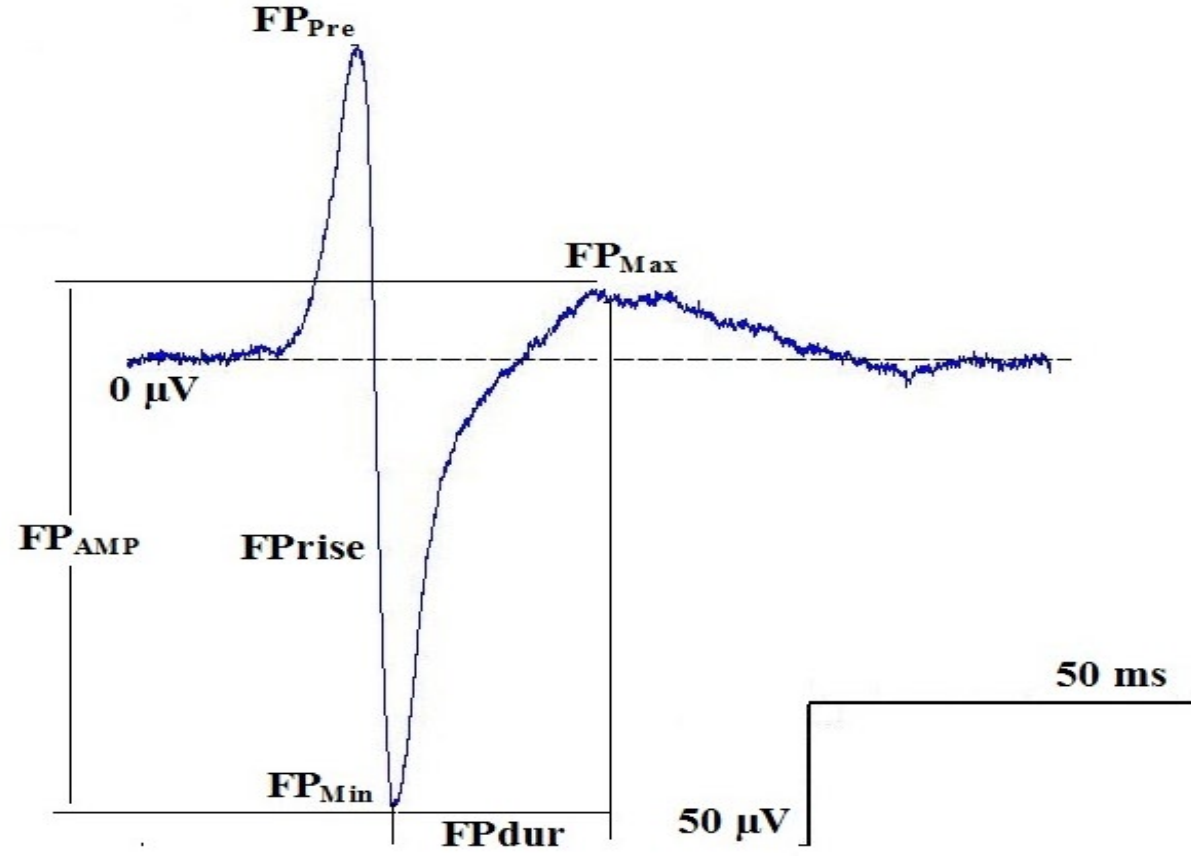

Fig. 1. A) Screen-dump from MC Rack (recording software for MEA system) with typical field potential (FP) signals from the HL-1 cell syncytium. Each square in the data window represents the corresponding unipolar FP recording from a single electrode. Observe various forms, amplitude and noise in the signals. B) Magnification of a clearly recorded FP with standardized nomenclature. Beating rate is calculated as signal spikes per second.

fitted with Boltzmann function for calculation of half maximum effect concentration $\left(\mathrm{EC}_{50}\right)$. Computer software IBM SPSS Statistics 19.0 (IBM Corporation, Somers, NY) and Origin 8.0 (Northampton, MA) were used for analysis of the data. Statistical significance was defined as $P<0.05$. 


\section{Cellular Physiology $\quad$ Cell Physiol Biochem 2012;30:477-488

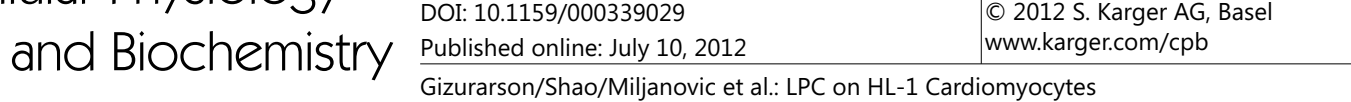

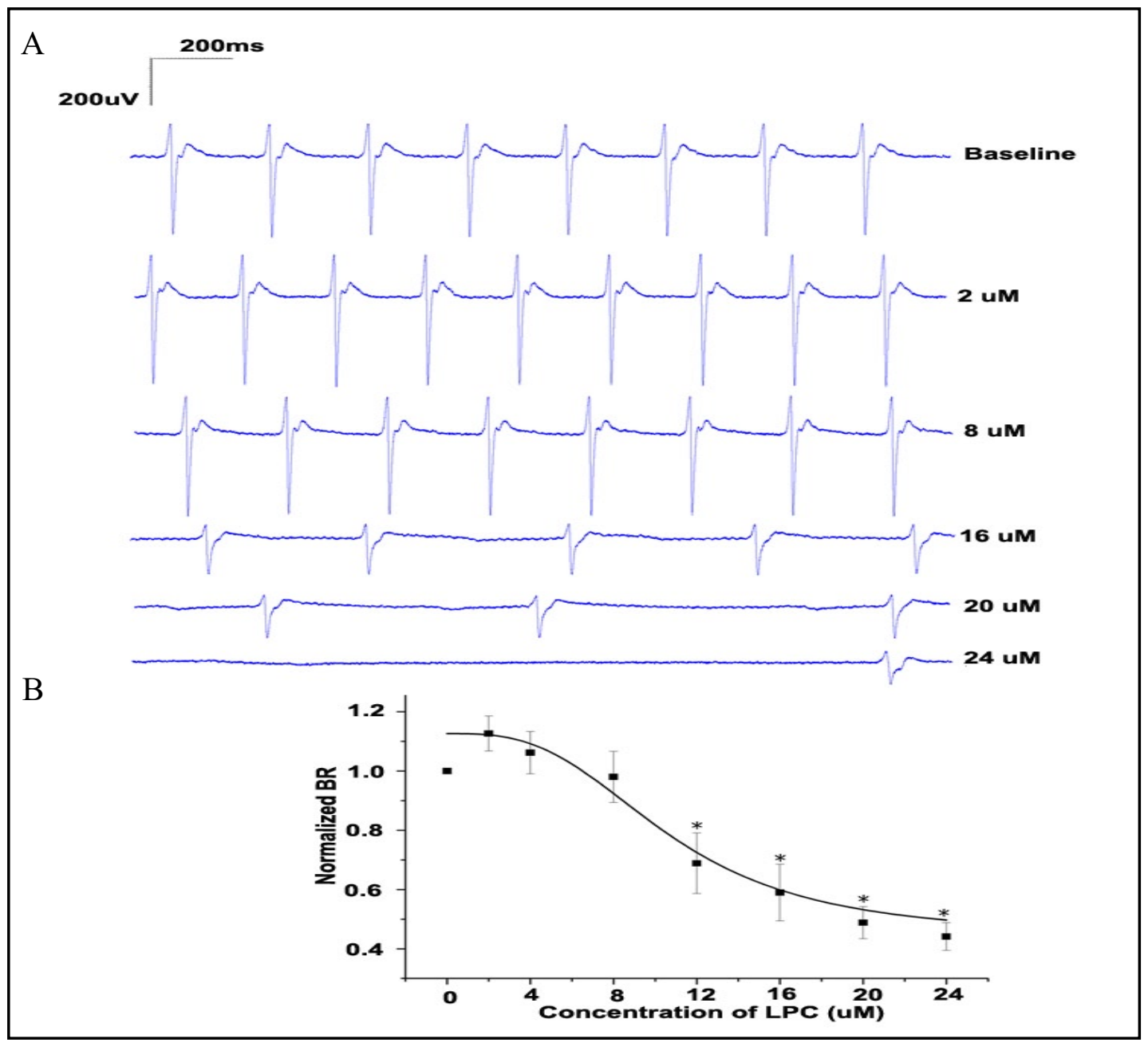

Fig. 2. Example of the effects of lysophosphatidylcholine (LPC) on beating rate (BR). A) Single electrode (FP) recording at different concentrations of LPC. Note that with increased concentration of LPC there is significant decrease in BR. B) Concentration-effect curve fitted with a Boltzmann function. ${ }^{*} \mathrm{P}<0.05$ compared with baseline.

\section{Results}

Properties of spontaneous electrical activity in the HL-1 syncytium under basal conditions

After $\sim 3$ days of growth in culture, spontaneously and synchronously beating HL-1 cells were present on the MEA plates. The cells produced characteristic FP signals (Fig. 1A). The signals were sustained for hours and did not change over time under experimental conditions. However, within a MEA plate, the morphologies of FP from the 60 electrodes varied (Fig. 1A). This variability in FP morphologies within one MEA chip can be attributed to several factors including variable relative position between electrode and cell, confluence state of the cells, inconsistent signal propagation direction among electrodes, damages to some electrodes, etc. However, we found that there was only one dominant pacemaker detected within a single MEA plate during the experiments, and no significant difference was documented in BR among individual electrodes. In one MEA plate, many cells may have pacemaker properties, but only the one with the highest intrinsic frequency (automaticity) acts as pacemaker. Signals recorded from the other electrodes in the plate therefore share the same BR as the effective 


\section{Cellular Physiology $\quad$ Cell Physiol Biochem 2012;30:477-488 \\ \begin{tabular}{ll|l} 
and Biochemistry & $\begin{array}{l}\text { DOI: 10.1159/000339029 } \\
\text { Published online: July 10, } 2012\end{array}$ & $\begin{array}{l}\text { C 2012 S. Karger AG, Basel } \\
\text { www.karger.com/cpb }\end{array}$ \\
\cline { 2 - 3 } & Gizurarson/Shao/Miljanovic et al.: LPC on HL-1 Cardiomyocytes
\end{tabular}}

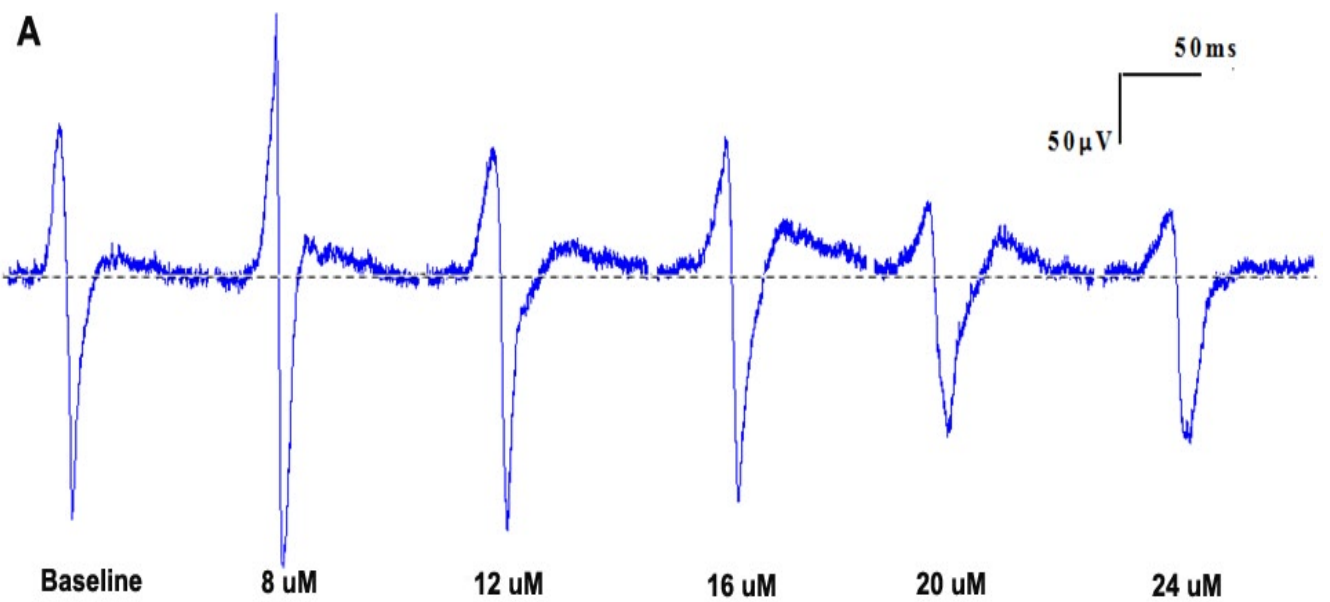

B

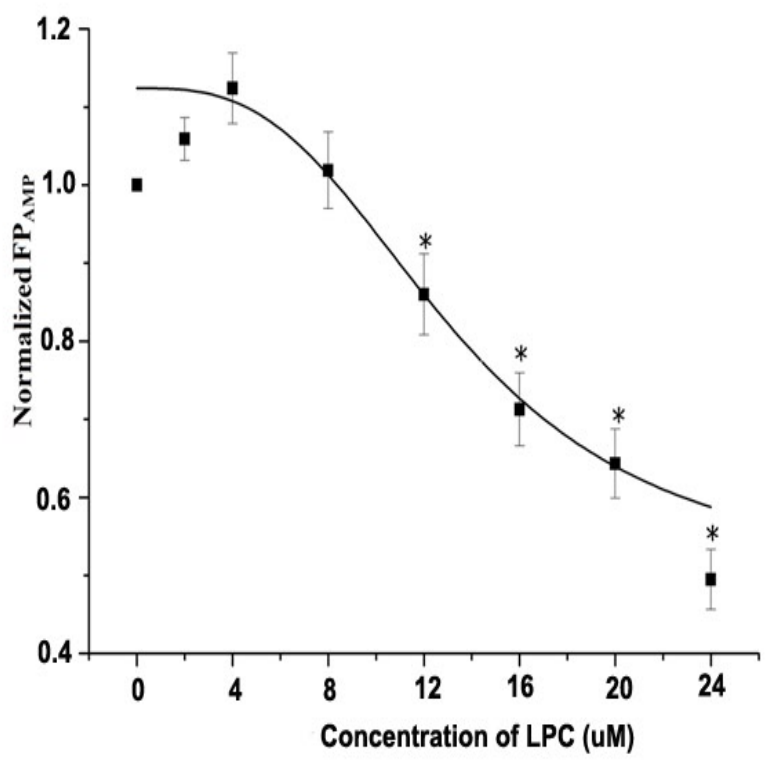

Fig. 3. Example of the effects of lysophosphatidylcholine (LPC) on field potential amplitude $\left(\mathrm{FP}_{\mathrm{AMP}}\right)$. A) A representative FP at different LPC concentrations. The low dose $(8 \mu \mathrm{M})$ increased the signal amplitude (nonsignificantly) but the amplitude then decreased significantly with higher doses. B) Concentration-effect curve fitted with a Boltzmann function. ${ }^{*} \mathrm{P}<0.05$ compared with baseline.

pacemaker. $\mathrm{FP}_{\mathrm{AMP}}$ showed a large variability in individual electrodes, within and between MEA plates (Fig. 1A). Among those plates tested, the largest range of $\mathrm{FP}_{\mathrm{AMP}}$ within a chip was between 9 and $890 \mu \mathrm{V}$. In contrast, there was no significant difference of $\mathrm{FP}_{\text {dur }}$ between electrodes within a MEA plate. Due to the homogeneity of HL-1 cardiomyocytes [16], HL1 syncytium within a plate shares the same pattern of depolarization and repolarization and thus show the same duration of FP once they are electrically activated. However, $\mathrm{FP}_{\text {dur }}$ may be incorrectly measured using automatic calculation with MC_Rack software or Matlab programmed tools if FP's with undetectable $\mathrm{FP}_{\text {Max }}$ are included in the analysis.

Electrophysiological effects of LPC on HL-1 cells

Addition of LPC had a concentration-dependent slowing effect on the BR of HL-1 cells (Fig. 2A). BR decreased steadily with increasing concentrations of LPC. EC ${ }_{50}$ for BR was $11.47 \pm 1.05 \mu \mathrm{M}$ (Fig. 2B). Similarly, LPC caused a concentration-dependent decrease in $\mathrm{FP}_{\mathrm{AMP}}$ (Fig. $3 \mathrm{~A}, \mathrm{~B}$ ). $\mathrm{EC}_{50}$ for $\mathrm{FP}_{\mathrm{AMP}}$ was $14.20 \pm 1.60 \mu \mathrm{M}$. $\mathrm{FP}_{\text {dur }}$ increased significantly at higher 


\section{Cellular Physiology $\quad$ Cell Physiol Biochem 2012;30:477-488 \\ \begin{tabular}{ll|l} 
and Biochemistry & $\begin{array}{l}\text { DOI: 10.1159/000339029 } \\
\text { Published online: July 10, } 2012\end{array}$ & $\begin{array}{l}\text { C 2012 S. Karger AG, Basel } \\
\text { www.karger.com/cpb }\end{array}$ \\
\cline { 2 - 3 } & Gizurarson/Shao/Miljanovic et al.: LPC on HL-1 Cardiomyocytes
\end{tabular}}

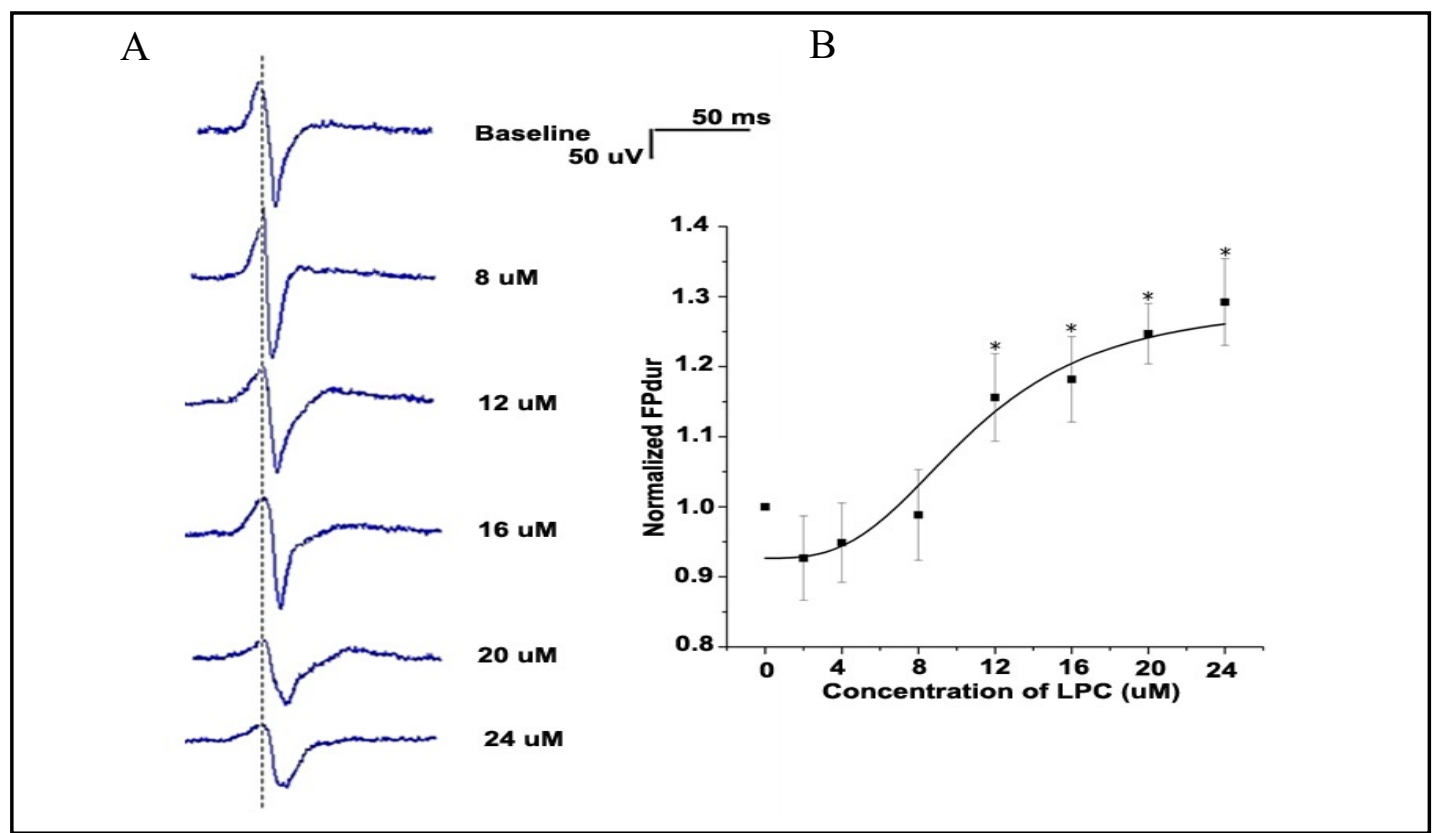

Fig. 4. Effects of lysophosphatidylcholine (LPC) on field potential duration $\left(\mathrm{FP}_{\mathrm{dur}}\right)$. A) A representative $\mathrm{FP}$ at different LPC concentrations. Note prolongation of $\mathrm{FP}_{\text {dur }}$ with increasing LPC concentration. Here only individual FP's are depicted, but the $\mathrm{FP}_{\max }$ is more accurately detected by averaging FP's. B) Concentrationeffect curve fitted with a Boltzmann function. ${ }^{*} \mathrm{P}<0.05$ compared with baseline.

LPC concentrations with $\mathrm{EC}_{50}$ of $12.06 \pm 1.78 \mu \mathrm{M}$ (Fig. 4). For all of the above parameters we noticed, at the lower concentrations of LPC, an initial trend in the opposite direction to the main finding (i.e. increase in $\mathrm{BR}$ and $\mathrm{FP}_{\mathrm{AMP}}$ and shortening in $\mathrm{FP}_{\text {dur }}$ ) Figs. $2 \mathrm{~B}, 3 \mathrm{~B}$ and $4 \mathrm{~B}$.

At LPC concentrations above $12 \mu \mathrm{M}$ we saw an increase in the incidence of premature beats (from outside the pacemaker region) and asynchronous beating patterns in the HL-1 syncytium (Fig. 5). The asynchronous beats were polymorphic (of different morphologies) and had irregular coupling intervals. $\mathrm{FP}_{\text {rise }}$ was prolonged in a concentration-dependent way. The prolongation of $\mathrm{FP}_{\text {rise }}$ was significant at doses of $>8 \mu \mathrm{M}$ (Fig. 6A). $\mathrm{EC}_{50}$ for $\mathrm{FP}_{\text {rise }}$ was 12.74 $\pm 1.29 \mu \mathrm{M}$.

\section{Delayed signal propagation in the HL-1 syncytium after $L P C$}

We included a total of 5 plates in the analysis of signal propagation. During LPC administration there was no change in the direction of propagation, but a concentrationdependent prolongation in signal propagation time (Fig. 6B). The maximum propagation time at the highest concentration of LPC $(24 \mu \mathrm{M})$ was delayed by $52.25 \pm 10.07 \mathrm{~ms}$ compared to baseline $(P<0.05)$.

The delayed signal propagation might be attributed to either decreased fast influx of $\mathrm{Na}^{+}$or inhibition of gap junctions. We therefore conducted experiments by blocking gap junctions with heptanol. At baseline there was no significant difference in propagation time between heptanol and LPC experiments. The propagation time was significantly increased by heptanol in a concentration-dependent manner (Fig. 6C, D). The maximum delay induced by heptanol was, however, significantly less than that induced by LPC. This suggests that the LPC-induced signal propagation delay may not be exclusively due to blockage of gap junctions, but may partly be related to slower cellular depolarization (i.e. prolonged $\mathrm{FP}_{\text {rise }}$ ). At low doses of LPC $(2-8 \mu \mathrm{M})$, when there was no prolongation of $\mathrm{FP}_{\text {rise }}$, the propagation time showed a trend towards delay, possibly due to impaired function of gap junction. Heptanol did not significantly modify $\mathrm{FP}_{\mathrm{AMP}}$ and $\mathrm{FP}_{\text {dur }}$ at the tested concentrations (Fig.6 E), in contrast to LPC administration, but decreased BR. 


\section{Cellular Physiology \\ Cell Physiol Biochem 2012;30:477-488 and Biochemistry

Fig. 5. Snap shots from a single electrode during lys ophosphatidylcholine (LPC) challenge. At higher concentrations of LPC, extra beats are seen with varying coupling intervals and morphology.

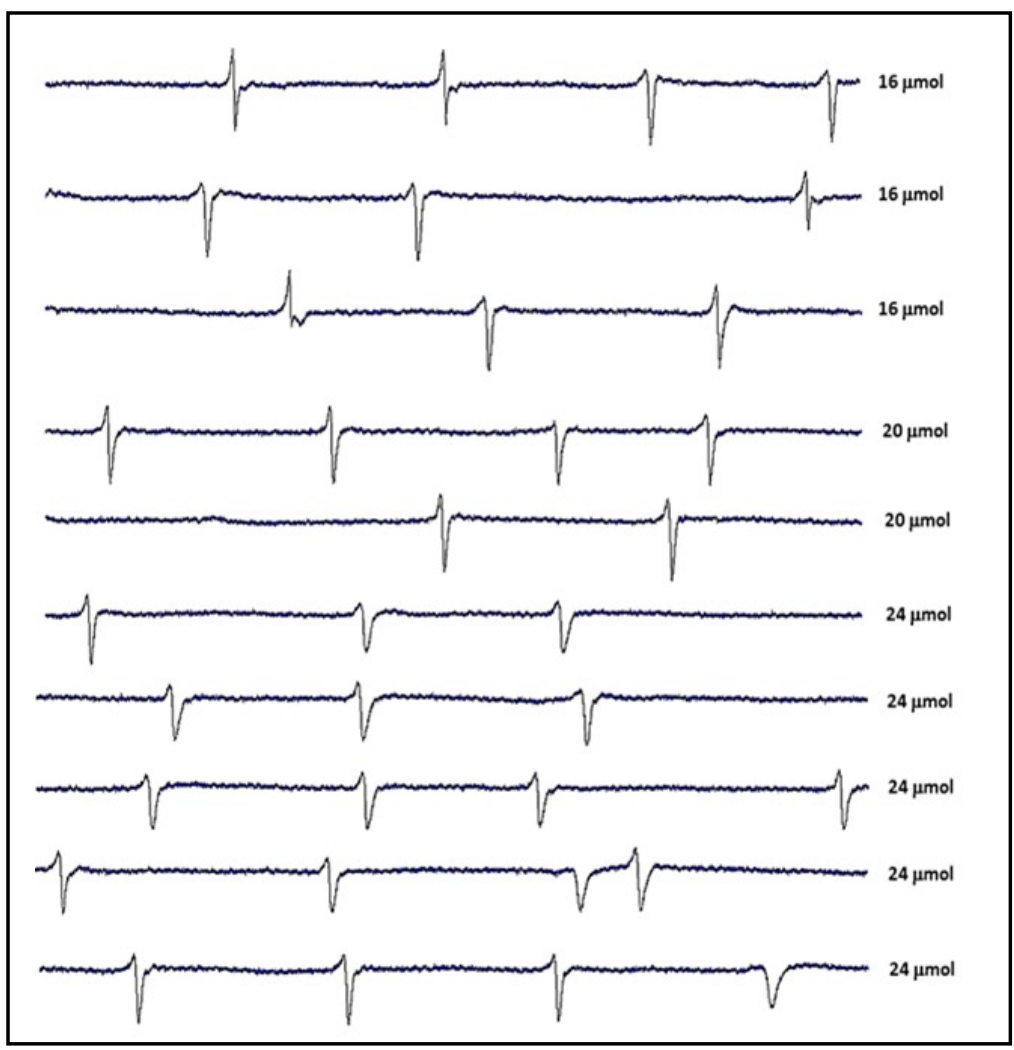

Isoprenaline and atropine induced attenuation of LPC effects

In order to further explore the negative chronotropic effects (i.e. decreased BR) of LPC on the HL-1 syncytium and the contribution of $\beta$-adrenergic receptors and/or muscarinic receptors, we first pre-treated HL-1 cells with ISO at $10 \mu \mathrm{M}$ for $3 \mathrm{~min}$ before LPC application. $10 \mu \mathrm{M}$ of ISO has been verified to have a strong positive chronotropic effect on HL-1 cells in our previous experiments. ISO pre-treatment did not alter the effects of LPC on FP parameters (i.e. $\mathrm{BR}, \mathrm{FP}_{\mathrm{AMP}}$ and $\mathrm{FP}_{\text {dur }}$; data not shown). However, we noticed that the LPC-induced decrease in propagation velocity was significantly attenuated after ISO pre-treatment (Fig. 7). On the other hand, ISO could not reverse the already reduced signal propagation velocity induced by LPC when administered afterwards (data not shown). Similarly, we tested the effects of muscarinic receptor blocker pre-treatment with atropine. We first defined the effective concentration of atropine and found that $50 \mu \mathrm{M}$ had a strong positive chronotropic effect on HL-1 cardiomyocytes . As for ISO, we showed that pre-treatment with atropine significantly attenuated the LPC-induced delay in signal propagation while no other apparent effects were observed on LPC-induced changes of the FP parameters.

\section{Discussion}

According to previous research LPC, which is accumulated during ischemia, has profound electrophysiological effects on cardiomyocytes. The aim of this study was to set up and validate an experimental in vitro model for studies of electrophysiological alterations during LPC challenge of cardiomyocytes (HL-1 cells) using MEA technology. We demonstrated in vitro inhibition of LPC on several electrophysiological properties of HL-1 cardiomyocytes and an attenuation of LPC-induced signal propagation delay with the pre-treatment of ISO and atropine. This in vitro model with HL-1 cells and MEA system may thus be a useful tool for preclinical studies of electrophysiological effects of different pathophysiological concepts, including myocardial ischemia. 


\section{Cellular Physiology $\quad$ Cell Physiol Biochem 2012;30:477-488 \\ \begin{tabular}{ll|l} 
and Biochemistry & $\begin{array}{l}\text { DOI: 10.1159/000339029 } \\
\text { Published online: July 10, } 2012\end{array}$ & $\begin{array}{l}\text { C 2012 S. Karger AG, Basel } \\
\text { www.karger.com/cpb }\end{array}$ \\
\cline { 2 - 3 } & Gizurarson/Shao/Miljanovic et al.: LPC on HL-1 Cardiomyocytes
\end{tabular}}
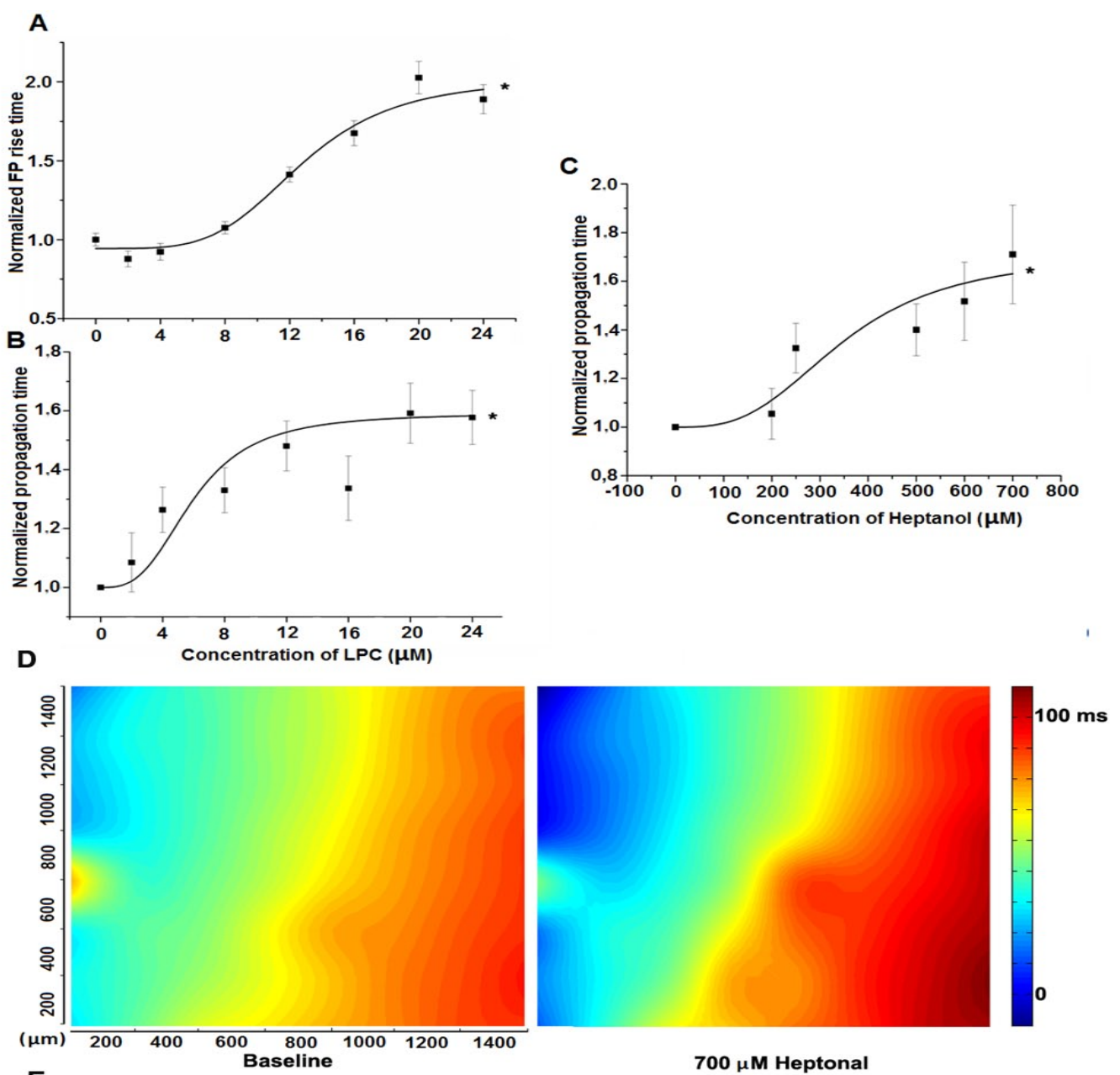

E

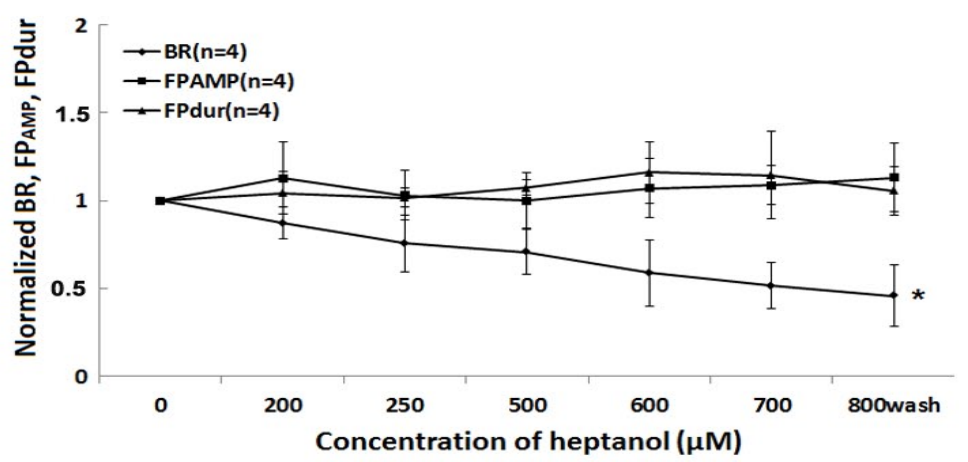

Fig. 6. Effects of lysophosphatidylcholine (LPC) and heptanol on field potential rise time (FP $\mathrm{rise}_{\text {) and signal }}$ propagation time. A) and B) Concentration-effect propagation time and rise time curves for LPC fitted with a Boltzmann function. C) Concentration-effect propagation time for heptanol fitted with a Boltzmann function. D) Representative colour maps showing slowed propagation with heptanol. E) Effect of heptanol on beating rate $(\mathrm{BR})$, field potential amplitude and duration $\left(\mathrm{FP}_{\mathrm{AMP}}\right.$ and $\mathrm{FP}_{\text {dur }}$, respectively) $* \mathrm{P}<0.05$, significant dosedependent effect.

LPC is an amphiphilic metabolite that is promptly released during myocardial ischemia in mammalian hearts, including the human heart. During ischemia, the production of LPC is increased by the action of phospholipase- $\mathrm{A}_{2}$ while the catabolism of LPC is markedly reduced resulting in rapid LPC accumulation [6, 21, 22]. Free concentrations of LPC in the ischemic myocardium is typically in the range of $10-30 \mu \mathrm{M}$, similar to the concentrations used in 


\title{
Cellular Physiology and Biochemistry
}

\author{
Cell Physiol Biochem 2012;30:477-488 \\ \begin{tabular}{l|l}
\hline DOI: $10.1159 / 000339029$ & C 2012 S. Karger AG, Basel
\end{tabular} \\ Published online: July 10, 2012 \\ www.karger.com/cpb
}

Fig. 7. Pre-treatment effect of isoprenaline (ISO) and atropine on lysophosphatidylcholine (LPC) induced depression of electrical activities of HL-1 cardiomyocytes. There is a significant effect of ISO and atropine in preventing the LPC-induced signal propagation delay. ${ }^{*} \mathrm{P}<0.05$, compared with LPC administration.

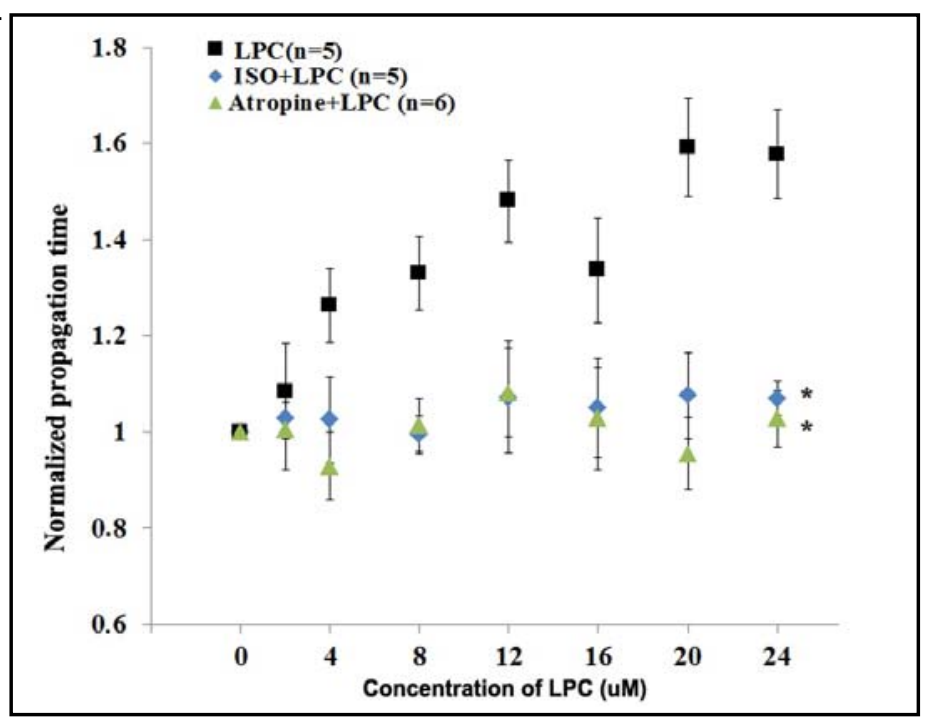

our model [23]. Our results are therefore likely to reflect the cellular effects of LPC during myocardial ischemia in the clinical setting.

LPC has been reported to affect several ion-channels. It reduces the upstroke of the action potential - an effect linked to inhibition of the peak sodium current [8]. This causes slowing of conduction, membrane depolarization and post-repolarization refractoriness [24]. Furthermore, LPC increases late inward $\mathrm{Na}^{+}$current via the formation of peroxynitrite [25] and inhibits $\mathrm{Na}^{+} / \mathrm{K}^{+}$ATP-ase [26], resulting in intracellular $\mathrm{Na}^{+}$accumulation and consequently $\mathrm{Ca}^{2+}$ accumulation (through the $\mathrm{Na}^{+} / \mathrm{Ca}^{2+}$ exchanger [9]). These effects prolong action potential duration (APD) and increase APD dispersion - both of which can be proarrhythmic and consistent with the present observation. LPC has been demonstrated to have an inhibitory effect on the normal pacemaker activity [27]. Sodium currents along with pacemaker currents $\left(\mathrm{I}_{\mathrm{f}}\right)$ play an important role in pacemaker activity of the HL-1 cells [28]. In our model, inhibitory effects of LPC on the inward $\mathrm{Na}^{+}$current and pacemaker current are reflected by the decrease in $\mathrm{FP}_{\mathrm{AMP}} \mathrm{BR}$, propagation velocity, and prolonged duration of $\mathrm{FP}$ rise time.

LPC also has complex effects on several potassium currents. The inwardly rectifying $\mathrm{K}^{+}$ current $\left(\mathrm{I}_{\mathrm{K} 1}\right)$ can be inhibited by LPC [7], which would be expected to cause prolongation of the APD. APD has been shown before to correlate well with $\mathrm{FP}_{\text {dur }}$ [14]. In support, we found that $\mathrm{FP}_{\text {dur }}$ was prolonged with higher concentrations of LPC. However, at low concentrations of LPC, the delayed rapid rectifier potassium current $\left(\mathrm{I}_{\mathrm{Kr}}\right)$ can be activated and induce shortening of the APD [29]. This may explain the non-significant trend for shortened $\mathrm{FP}_{\mathrm{dur}}$ observed at lower concentrations of LPC in the present study.

LPC is a potent inhibitor of myocardial gap junction function [30]. We found that signal propagation was significantly delayed by LPC. Compared to heptanol (a selective gapjunction blocker), LPC seems to affect propagation time to a similar extent. The delayed signal propagation caused by gap-junction inhibition is, however, likely to be further aggravated by decreased inward $\mathrm{Na}^{+}$current and increased intracellular $\mathrm{Ca}^{2+}$ overload [31] induced by LPC.

In additional series of experiments, we unexpectedly found that the LPC-induced delay in the signal conduction of HL-1 cells could almost be completely prevented by pre-treatment with ISO or atropine. The mechanism for this is not clear, but it may be related to ISO-induced potentiation in gap junction function. It has been reported that $\beta$-adrenoceptors activation up-regulates gene expressions of $\mathrm{Cx} 40$ and $\mathrm{Cx} 43$, two important proteins of gap junction in cardiomyocytes, through a protein-kinase A (PKA) dependent pathway [32]. The short pre-treatment period (three minutes) suggests that other mechanisms than up-regulation of connexion genes may be contributing in our system. 


\section{Cellular Physiology Cell Physiol Biochem 2012;30:477-488 \\ \begin{tabular}{ll|l} 
and Biochemistry & $\begin{array}{l}\text { DOI: 10.1159/000339029 } \\
\text { Published online: July 10, } 2012\end{array}$ & $\begin{array}{l}\text { C 2012 S. Karger AG, Basel } \\
\text { www.karger.com/cpb }\end{array}$ \\
\cline { 2 - 3 } Gizurarson/Shao/Miljanovic et al.: LPC on HL-1 Cardiomyocytes
\end{tabular}}

In conclusion, this is the firststudy to examine effects of LPC on HL-1 cardiomyocytes using a multichannel MEA system. We have verified that LPC induces several electrophysiological alterations of the cardiomyocytes. An important advantage of the method is the possibility to analyze the net-effects of all cellular events elicited by experimental perturbation (e.g. caused by addition of an exogenous substance) on electrical properties, frequency, and rhythm, which provides the possibility to perform high-throughput screening of different pro-arrhythmic and anti-arrhythmic substances. The information gathered from this model can be complementary to that obtained from the existing in vitro cellular models and in vivo animal models.

Among the limitations of our cell model is that immortalized HL-1 cell-line preserves characteristics more similar to atrial than ventricular cardiomyocytes and may differ from normal adult cardiomyocytes. In this study we have chosen one substance (LPC), but several other substances are likely to participate in the electrophysiological changes seen during ischemia. We have neither monitored nor experimentally manipulated $\mathrm{pH}$ or electrolyte composition.

The incubation time of LPC on the HL-1 cells is relatively short in the present study. The observed electrophysiological effects of LPC in our model were almost completely reversible by washout. This indicates that LPC is incorporated into the sarcolemma and interact directly with membrane channels and pump, but does not cause irreversible damage to the cell membrane (i.e. electroporation), at least not during short term challenge with LPC.

To further understand the participation of individual ion channels in the observed electrophysiological alterations, various blockers and enhancers of specific ion channels could be utilized in the present model in the future.

\section{Acknowledgements}

The study was supported by grants from the Swedish Heart and Lung Foundation, the Swedish Research Council, Gothenburg Medical Society, Sahlgrenska University Hospital, and the Swedish Medical Society.

\section{References}

1 Moss AJ: Preventing heart failure and improving survival. N Engl J Med 2010;16;363:2456-2457

2 Yesil M: Management of arrhythmias during transport in patients with acute myocardial infarction. Anadolu Kardiyo. Berg 2007;7 Suppl 1:85-7.

3 Cascio WE, Yang H, Muller-Borer BJ, Johnson TA: Ischemia-induced arrhythmia: The role of connexins, gap junctions, and attendant changes in impulse propagation. J Electrocardiol 2005;38:55-59.

4 Watanabe M, Okada T: Lysophosphatidylcholine-induced myocardial damage is inhibited by pretreatment with poloxamer 188 in isolated rat heart. Mol Cell Biochem 2003;248:209-215.

5 Corr PB, Yamada KA, Creer MH, Sharma AD, Sobel BE: Lysophosphoglycerides and ventricular fibrillation early after onset of ischemia. J Mol Cell Cardiol 1987;19:S45-53.

6 Sobel BE, Corr PB, Robison AK, Goldstein RA, Witkowski FX, Klein MS: Accumulation of lysophosphoglycerides with arrhythmogenic properties in ischemic myocardium. J Clin Invest 1978;62:546-553.

7 Kiyosue T, Arita M: Effects of lysophosphatidylcholine on resting potassium conductance of isolated guinea pig ventricular cells. Pflügers Archiv 1986;406:296-302.

8 Undrovinas AI, Fleidervish IA, Makielski JC: Inward sodium current at resting potentials in single cardiac myocytes induced by the ischemic metabolite lysophosphatidylcholine. Circ Res 1992;71:1231-1241.

9 Sedlis SP, Corr PB, Sobel BE, Ahumada GG: Lysophosphatidyl choline potentiates $\mathrm{Ca}^{2+}$ accumulation in rat cardiac myocytes. Am J Physiol 1983;244:H32-38.

10 Zheng M, Wang Y, Kang L, Shimaoka T, Marni F, Ono K: Intracellular Ca ${ }^{2+}$ - and PKC-dependent upregulation of t-type $\mathrm{Ca}^{2+}$ channels in LPS-stimulated cardiomyocytes. J Mol Cell Cardiol 2010;48:131-139. 


\section{Cellular Physiology Cell Physiol Biochem 2012;30:477-488 \begin{tabular}{ll|l} 
and BiOChemistry & $\begin{array}{l}\text { DOI: 10.1159/000339029 } \\
\text { Published online: July 10, } 2012\end{array}$ \\
$\begin{array}{ll}\text { Gizurarson/Shao/Miljanovic et al.: LPC on HL-1 Cardiomyocytes } \\
\text { www.karger.com/cpb }\end{array}$
\end{tabular}}

11 Karli JN, Karikas GA, Hatzipavlou PK, Levis GM, Moulopoulos SN: The inhibition of $\mathrm{Na}^{+}$and $\mathrm{K}^{+}$stimulated atpase activity of rabbit and dog heart sarcolemma by lysophosphatidyl choline. Life Sci 1979;24:18691875.

12 Daleau P: Ethanol protects against lysophosphatidylcholine-induced uncoupling of cardiac cell pairs. Pflugers Arch 2002;445:55-59.

13 Hescheler J, Halbach M, Egert U, Lu ZJ, Bohlen H, Fleischmann BK, Reppel M: Determination of electrical properties of es cell-derived cardiomyocytes using meas. J Eectrocardiol 2004;37 Suppl:110-116.

14 Halbach M, Egert U, Hescheler J, Banach K: Estimation of action potential changes from field potential recordings in multicellular mouse cardiac myocyte cultures. Cell Physiol Biochem 2003;13:271-284.

15 Reppel M, Igelmund P, Egert U, Juchelka F, Hescheler J, Drobinskaya I: Effect of cardioactive drugs on action potential generation and propagation in embryonic stem cell-derived cardiomyocytes. Cell Physiol Biochem 2007;19:213-224.

16 Claycomb WC, Lanson NA, Jr., Stallworth BS, Egeland DB, Delcarpio JB, Bahinski A, Izzo NJ, Jr.: Hl-1 cells: A cardiac muscle cell line that contracts and retains phenotypic characteristics of the adult cardiomyocyte. Proc Natl Acad Sci USA 1998;95:2979-2984.

17 Sawai T, Lampman R, Hua Y, Segura B, Drongowski RA, Coran AG, Harmon CM: Lysophosphatidylcholine alters enterocyte monolayer permeability via a protein kinase $\mathrm{C} / \mathrm{Ca}^{2+}$ mechanism. Pediatric surgery international 2002;18:591-594.

18 Reppel M, Pillekamp F, Lu ZJ, Halbach M, Brockmeier K, Fleischmann BK, Hescheler J: Microelectrode arrays: A new tool to measure embryonic heart activity. J Electrocardiol 2004;37:S104-109.

19 Halbach M, Egert U, Hescheler J, Banach K: Estimation of action potential changes from field potential recordings in multicellular mouse cardiac myocyte cultures. Cell Physiol Biochem 2003;13:271-284.

20 Banach K, Halbach MD, Hu P, Hescheler J, Egert U: Development of electrical activity in cardiac myocyte aggregates derived from mouse embryonic stem cells. Am J Physiol Heart Circ Physiol 2003;284:H21142123.

21 Kinnaird AA, Choy PC, Man RY: Lysophosphatidylcholine accumulation in the ischemic canine heart. Lipids 1988;23:32-35.

22 Corr PB, Yamada KA, Creer MH, Sharma AD, Sobel BE: Lysophosphoglycerides and ventricular fibrillation early after onset of ischemia. J Mol Cell Cardiol 1987;19:S45-53.

23 Liu SY, Yu CH, Hays JA, Panagia V, Dhalla NS: Modification of heart sarcolemmal phosphoinositide pathway by lysophosphatidylcholine. Biochim Biophys Acta 1997;1349:264-274.

24 Antzelevitch C, Burashnikov A: Atrial-selective sodium channel block as a novel strategy for the management of atrial fibrillation. Ann N Y Acad Sci 2010;1188:78-86.

25 Gautier M, Zhang H, Fearon IM: Peroxynitrite formation mediates lpc-induced augmentation of cardiac late sodium currents. J Mol Cell Cardiol 2008;44:241-251.

26 Karli JN, Karikas GA, Hatzipavlou PK, Levis GM, Moulopoulos SN: The inhibition of $\mathrm{Na}^{+}$and $\mathrm{K}^{+}$stimulated atpase activity of rabbit and dog heart sarcolemma by lysophosphatidyl choline. Life Sci 1979;24:1869. 1875.

27 Hu YM, Zhang Z, Gao RB, Xu YQ: [effect of lysophosphatidylcholine on the pacemaker current i(f) of sheep cardial purkinje fibers in ischemia-like condition]. Sheng Li Xue Bao 1997;49:513-520.

28 Law JK, Yeung CK, Hofmann B, Ingebrandt S, Rudd JA, Offenhäusser A, Chan M: The use of microelectrode array (mea) to study the protective effects of potassium channel openers on metabolically compromised hl-1 cardiomyocytes. Physiol meas 2009;30:155-167.

29 Bai Y, Wang J, Lu Y, Shan H, Yang B, Wang Z: Phospholipid lysophosphatidylcholine as a metabolic trigger and herg as an ionic pathway for extracellular k accumulation and "short qt syndrome" in acute myocardial ischemia. Cell Physiol Biochem 2007;20:417-428.

30 Daleau P: Lysophosphatidylcholine, a metabolite which accumulates early in myocardium during ischemia, reduces gap junctional coupling in cardiac cells. J Mol Cell Cardiol 1999;31:1391-1401.

31 Tribulova N, Seki S, Radosinska J, Kaplan P, Babusikova E, Knezl V, Mochizuki S: Myocardial Ca ${ }^{2+}$ handling and cell-to-cell coupling, key factors in prevention of sudden cardiac death. Can J Physiol Pharmacol 2009;87:1120-1129.

32 Salameh A, Dhein S: Adrenergic control of cardiac gap junction function and expression. Naunyn Schmiedebergs Arch Pharmacol 2011;383:331-346. 